\title{
Reengineering Lead to Cash - Process and Organization
}

\author{
Giorgio Rimini ${ }^{1}$, Paolo Roberti ${ }^{2}$ \\ ${ }^{1}$ British Telecom, Italy, Giorgio.rimini@bt.com \\ ${ }^{2}$ Business Integration Partners, Italy, Paolo.Roberti@mail-bip.com
}

\begin{abstract}
In the last few years, BT Italy has recorded an important business growth, which has led to a high complexity and a request to improve governance of fulfilment process. This paper presents the BT Italy case study of reengineering the Lead to Cash business processes to reduce time to market and improve customer's satisfaction. The operational levers applied to realize project objectives are business process reengineering, organizational review and tools enhancement. In the process reengineering "Performing process methodology" and Higo framework have been applied. The first part of the paper presents the BT scenario, the second part describes the process reengineering and the organizational interventions. The last paragraph presents the expected benefits and the conclusion of the case study.
\end{abstract}

Keywords: Business Process reengineering, Centralization of customer request, Business Process Management

\section{Introduction}

Since last years, the Italian Telecommunication Industry has experienced a growing competition rate. Acquiring a new customer and retaining an existing one is more challenging than before. Operators need to have lean-and-customeroriented processes to build a competitive advantage.

This paper presents the case study of BT Italy, which has reengineered the Lead to Cash business process to reduce time to market and improve customer's satisfaction. The lead-to-cash process goes from initial contact, to sale, to service delivery, to payment collection. Lead-to-Cash represents in Telecommunication market one of the most significant areas to build customer satisfaction and to acquire competitiveness. Given these conditions, competition is in the way services are produced and delivered rather than in the nature of the service itself. The first paragraph describes the BT Italy as-is scenario, the second illustrates the 
business process reengineering intervention, and the third presents expected benefits and conclusions.

\section{Framework}

Service competitiveness is based on process level of performances. In the modern management theory, a process is competitive if it is more profitable, delivers a better quality and service than other ones. In this sense, engineering of service processes represent a critical success factor. A competitive service process should also be sustainable. A process is sustainable if it can maintain competitive performances over time. To be sustainable process performances should be acceptable to the process stakeholder communities. Process stakeholders and performance measurement are integrated in a conceptual grid called $\mathrm{Higo}^{\mathrm{R}}[5,6]$ that considers performances not only for managers and customers but also for workers. In BT Italy case, Higo concepts have been used to improve lead-to-cash processes in a performing conception. "Performing process methodology" has been applied in this case study and it has been articulated in the following phases:

1. Define process performance

2. Model process flow

3. Design process cockpits

All stakeholders have been involved in the project activities with interviews, analysis etc. People at all levels of organization (operator, manager and director) contributed to the project, with a strong commitment of the CEO and Top Management.

The process reengineering focused on interventions which implied significant outcomes in terms of swiftness of execution and adaptability to existing context, in order to rapidly improve competitiveness and assure sustainability in a long term vision.

\section{BT Italy scenario}

BT Italy is a major provider in Italy of data, voice and internet services to corporate customers. The competitive advantage has been guaranteed by BT capacity of providing customized solutions to its customers. High-customized offers entail low standardization of processes and increasing degrees of complexity, hardly compatible with an efficient industrialized approach. For those reasons, two-parallel chains have been implemented to activate services: customized chain, for complex products; and standardized. The business growth has led to a high complexity and a complex governance of the lead to cash 
processes, which have reached industrial volumes but kept craft made processes and product catalogues.

In the last years, several projects had taken place. Nevertheless, they brought mainly limited results due to the focus more on tools than processes, and to the use of approaches that considered top management's views of the problem without a check on operational activities. Therefore, a further initiative started on May 2007. This project, namely Eleven, was run by the support of Business Integration Partners, a consulting firm.

\section{The project "Eleven"}

The project "Eleven" started on May 2007 with the following objectives:

- Reduce time to market and optimize quality in order to offer a wide range of service customized into comprehensive solutions that exactly fits to customer needs

- Increase operational efficiency and focalize sales team on customer relations and acquisition of new market share.

- "Eleven" is composed by the following steps:

- Step 1, focused on diagnosis of the main critical situation and to produce a master plan of the intervention required

- Step 2, focused on engineering the to-be solution.

The duration of the project was about 8 months.

The operational levers applied to realize project objectives were: business process reengineering, organizational review and tools enhancement.

\section{Eleven Step 1}

The first phase aimed to analyze the as-is scenario by designing all processes, identifying and prioritizing issues, defining intervention areas and plan.

Supported by the lesson learned from previous experiences, it has been considered both Top Management and Business Operators' point of views. A lot of effort was spent to verify continuously the impact of some top-down decisions to the daily operations. More than 100 interviews were done with directors, managers and operators. More than 50 employees contributed actively to it. 


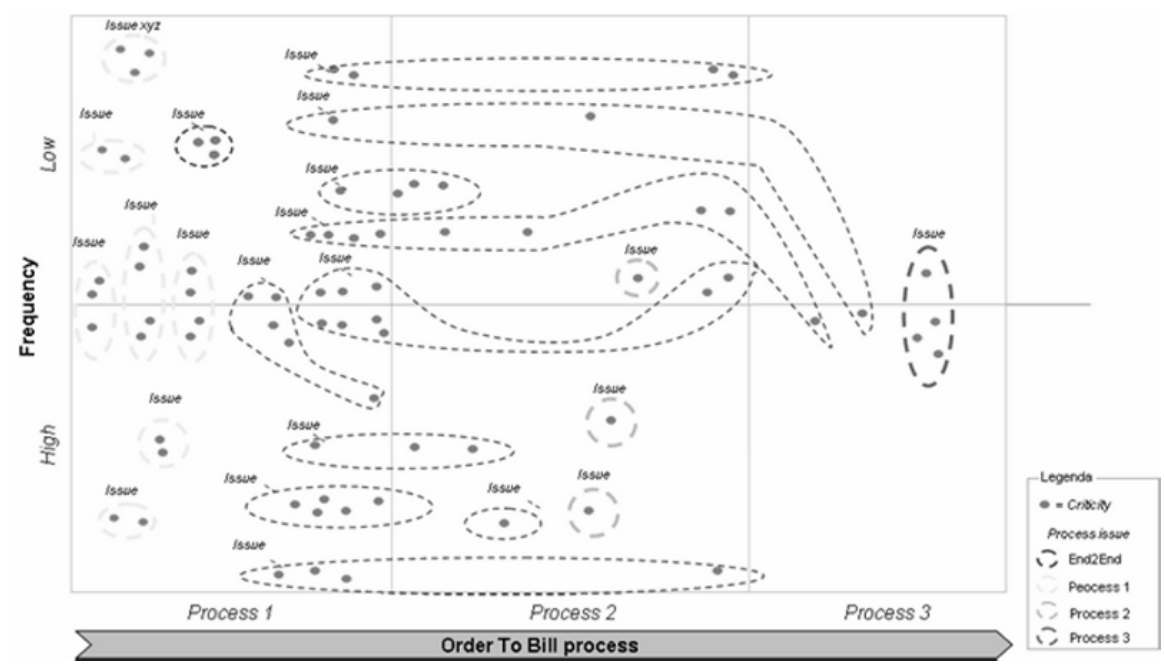

Fig.1. Main issues diagram

\section{Eleven Step 2}

The second phase has mainly developed the following streams:

- Business Process Reengineering: focalized on lead to cash processes which ranges from customer's contract signature to customer's service delivery (translate order contract)

- Information heritage: order content standardization in terms of owner, utilization of data and tracking form

- Organizational Review: creation of a new organizational structure and formalization of the operational responsibilities of single actors involved

- Business Process Monitoring: implementation of a monitoring tool to measure process performance

\section{Evolutionary Model}

In order to realize project objectives and to guarantee an overall vision of the change roadmap, it has been created a reference Order Management model to be built in BT Italy. 


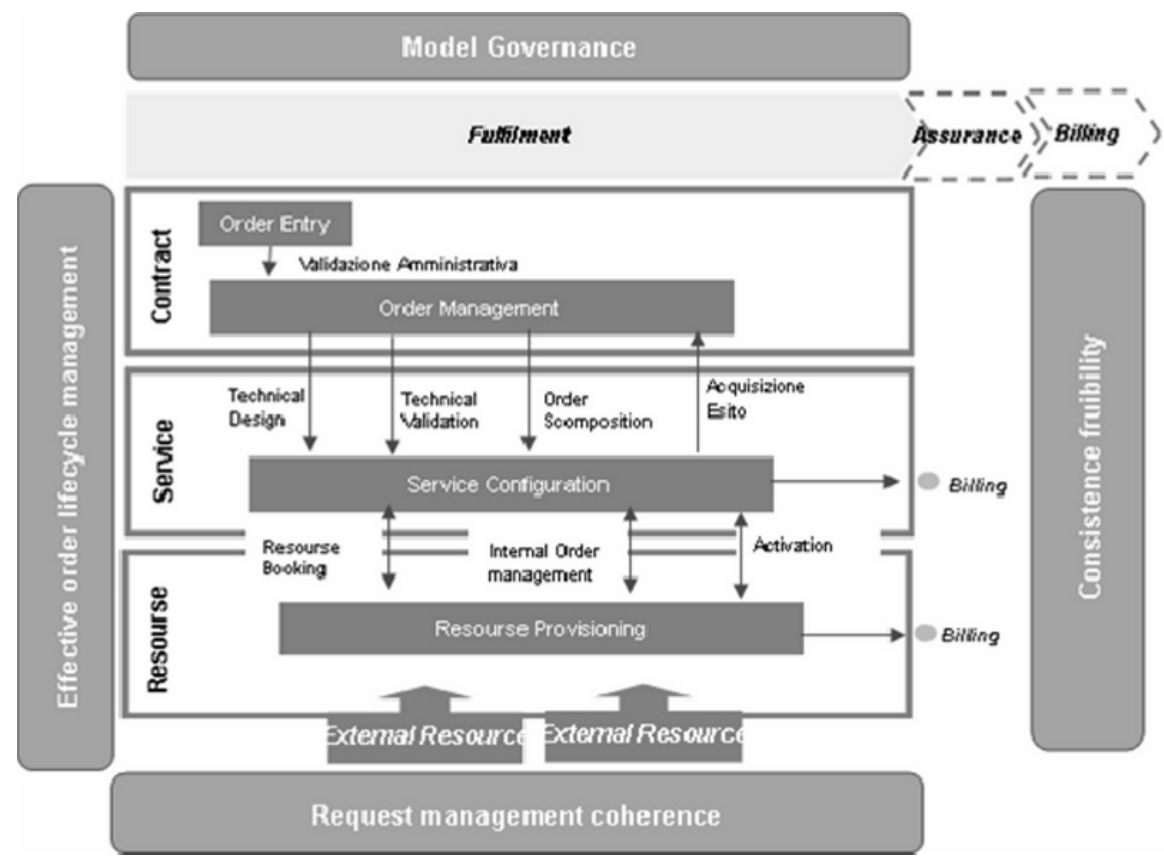

Fig.2. Evolutionary Model

The evolution is delivered by a two-stage approach:

Stage 1: the main focus is processes and organization. In this phase we minimized the impact on IT systems to facilitate the changes adoptions;

Stage 2 the main focus is enhancing IT systems to support activities, to tune processes and to develop a structured order management model based on a workflow management system

Eleven step 2 is aimed to realize evolution stage 1 in terms of processes and organizational intervention.

\section{Business Process Reengineering}

The BPR was focused on customized delivery chain and it has provided punctual intervention to the standardized chain for all customer segments.

The customized delivery chain is referred to non-standard product and presented the most significant problems and the principal margin of optimization in terms of efficiency and effectiveness.

The key-elements that have driven BPR are described below:

- Centralization of customer request: operational process oriented to the customer total request instead of single product order 
- Structured Activities: improvement of operational efficiency of the order lifecycle

- Information availability and solidness: order content standardization in each phase of process in terms of owner and compulsoriness

- Parallelizability and simplification: manual activities automation and deletion of duplication by a deep review of order content and information supplying flow

- Process Governance: definition of a new organizational unit dedicated to Translate Order Contract process management and punctual tracking of timing and owner of process execution. Translate Order Contract is the process from customer's contract signature to the beginning of contract delivery.

For every single key element, specific interventions have been defined in terms of processes, organization and systems. The intervention brings synergy to the Stage 1 of the Order Management Model.

\section{Organizational Intervention}

The most relevant needs in terms of organization were:

- Creation of a new structure, the TOC Room, responsible of the translate order contract activities and able to guarantee the process governance

- Definition of a specialist unit, the Low Level Design Group, responsible of low level design customer solution for non standard complex product

\section{Toc Room}

The new solution governance is guaranteed by the creation of an organizational unit responsible of the translation of contract in clean orders workable by delivery units. The new structure implies an overall simplification of the as-is scenario, in which the TOC activities were fragmented on 4 different divisions in a best effort approach.

The significant novelty of this intervention consists in the assignment of the punctual responsibility of the Translate Order Contract activities in terms of timing and quality.

Toc Room positioning has been defined balancing need to create synergy with sales division and the requirement of independency of the new structure that would have been able to coordinate sales and delivery activities on customer orders.

The organizational microstructure has been defined by activities classification in terms of required level of responsibility and standardization level.

The TOC Room dimension has been defined in the hypothesis of three in sourcing levels to guarantee a high level of quality, cost control and acceptable timing. 


\section{Low Level Design Group}

One of the most relevant problem in the as-is scenario was the gap of responsibility in customer solution low level design

This gap implied recycle and partial overlapping of activities and also the increase of time to market.

The Eleven project has defined:

- A task force responsible of this activities

- Engagement rules to involve the LLD Group

- Low level design scope and content

- Dimension and positioning.

\section{Business Process Monitoring}

In order to achieve the governability objectives Eleven has developed a performance measurement framework. The BT Italy model is based on HIGO framework. It is based on four performance classes: Time, Quality, Volumes and Economics.

Time: It groups all indicators measuring the time by which activities are completed

Quality: This class monitors the quality of the main activities, suck as order that cannot be completed.

Volumes: This class monitors the volumes of orders either work-in-progress or completed

Economics: This class monitors the immobilized amount of money behind work-in-progress orders or order that cannot be completed.

The model is based on a hierarchy of indicators to allow multi-level analysis from the end-to-end process to the critical activities to be monitored. We have allowed both high level (Top Managers) and operational level (team players manager) monitoring.

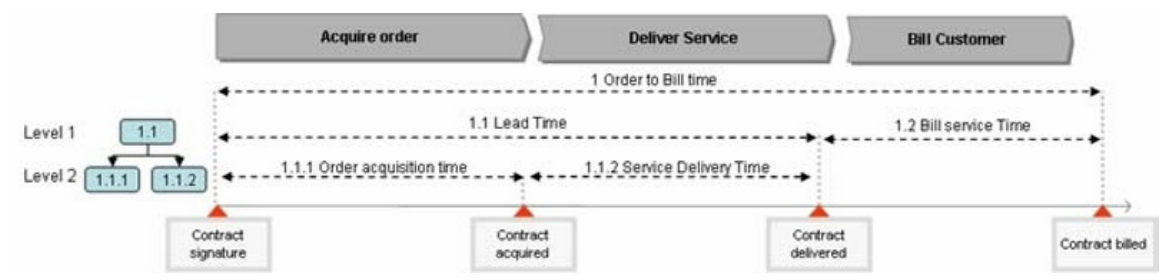

Fig.3. KPIs hierarchy

The figure above shows an example of hierarchy for KPIs of the class Time. We have broken the main process down into activities which are critical to the business performance. Each activity is uniquely associated to an organizational 
structure. In this way we have been able to measure the players' contribution to the overall process performance.

The model has been developed in a web-based dashboard that allows BT Italy to measure and monitor the order to bill process.

\section{Conclusions}

The project Eleven is perceived by BT Italy as a successful business process reengineering. The applied methodology and the shared approach have facilitated a spread consensus among employees, which have contributed proactively to project activities.

Main success factors have been:

Collaborative approach, which has led all key players to actively participate on the solution definition, and to share improvement logics and operational choices.

Pragmatism and quick-wins focus, which have led to a wide perception of the project as an effective vehicle to improve operational activities.

Synergic combination of levers, such as organization, processes and tools, to identify the most effective solution matching the evolving needs of the context.

The intervention is expected to improve the process performance by reducing the lead time of the lead to cash chain, increasing operating efficiency and reduce manual activities.

\section{References}

1. Bartezzaghi E., Dove va il BPR?, Mondo Digitale, n.2, pp. 27-49, 2002

2. Davenport T.H., The Coming Commmoditization of Processes, Harvard Business Review, June 2005

3. Davenport T.H., Mission Critical: Realizing the Promise of Enterprise Systems, 2000

4. Henry Mintzberg, La progettazione organizzativa, Il Mulino, Bologna, 1996

5. Longo A., Motta G., Designing Business Process for sustainable performance: a model and a method, Business Process Design Workshop, 3d International Conference on Business Process Management, Nancy 5-7 September 2005

6. Motta G., Pignatelli G., Competitività e sostenibilità dei processi gestionali, AICA, Milan, 2007

7. Klein M., Herman G.A., Lee J., O’Donnel E., Malone T.H., "Inventing new business process using a process repository", in Malone T.H., Crowston K., Herman G.A., Organizing Business Knowledge - the MIT process handbook, The MIT press, Cambridge Ma., 2003

8. Enhanced Telecom Operation Model (eTOM) The Business Process Framework for the Information and Communication Service Industry, TeleManagement Forum, November 2005

9. Parmenter D., Key Performance Indicators: Developing, Implementing,and Using Winning KPIs, John Wiley \& Sons, New Jersey, March 2007. 